\title{
Bleeding and fetal Doppler parameter
}

To the Editor,

The report on "bleeding and fetal Doppler parameter" is very interesting (1). Iskender et al. reported that "bleeding during genetic amniocentesis did not change umbilical artery and middle cerebral artery Doppler parameters (1)." The finding might not applicable to all cases. In cases with pathology, an aberration might be possible. For example, in the case with intrauterine growth restriction (IUGR), of which the parameter is usually abnormal $(2,3)$, the effect should be specifically studied. A similar consideration for the case with polyhydramnios (4) should be mentioned as well.

\section{Sim Sai Tin ${ }^{1}$, Viroj Wiwanitkit ${ }^{2}$ \\ ${ }^{1}$ Department of Medical Center, Shantou Medical Center, Shantou, China \\ ${ }^{2}$ Department of Tropical Medicine, Hainan Medical University, Hiakou, China}

\section{References}

1. Iskender C, Tanm E, Cok T, Kalaycı H, Parlakgümüş A, Yalçınkaya C. Does bleeding affect fetal Doppler parameters during genetic amniocentesis? J Turk Ger Gynecol Assoc 2014; 15: 100-3. [CrossRef]

2. Baschat AA, Gembruch U, Reiss I, Gortner L, Weiner CP, Harman CR. Relationship between arterial and venous Doppler and perinatal outcome in fetal growth restriction. Ultrasound Obstet Gynecol 2000; 16: 407-13. [CrossRef]

3. Ferrazzi E, Bellotti M, Galan H, Pennati G, Bozzo M, Rigano S, Battaglia FC. Doppler investigation in intrauterine growth restriction-from qualitative indices to flow measurements: a review of the experience of a collaborative group. Ann N Y Acad Sci 2001; 943: 316-25. [CrossRef]

4. Mari G, Wasserstrum N, Kirshon B. Reduction in the middle cerebral artery pulsatility index after decompression of polyhydramnios in twin gestation. Am J Perinatol 1992; 9: 381-4. [CrossRef]

\section{Author's Response}

We thank the authors for their valuable comments on our study. The main concern raised by the authors is that our findings may not be applicable to all patients, particularly those with obstetrical complications such as intrauterine growth restriction (IUGR) or polyhydramnios. Additionally, the authors suggested that the effects of amniocentesis should be studied specifically under these circumstances. While these suggestions are worthwhile to consider, they seem to miss the point of the present study because of a number of reasons. The sole purpose of this observational study was to investigate whether midtrimester amniocentesis through the transplacental route had any significant effect on fetal hemodynamic parameters (1). To eliminate potential confounders, patients with aneuploidy were excluded. In our cohort, there were no cases of very early IUGR, which is a relatively rare condition with a diverse etiology. The majority of cases are associated with fetal anomalies, aneuploidies, or infections (2). Considering the etiological diversity of very early IUGR, we doubt whether the impact of placental manipulation during amniocentesis in these patients would be of any clinical significance without a proper methodology. A similar consideration is also valid for polyhydramnios, which is related to a higher incidence of associated fetal abnormalities especially when related to IUGR or preterm birth (3).

Having stated that, we would like to mention that we totally agree with the authors who suggested that the effects of amniocentesis should be studied specifically under these circumstances. As suggested by our findings and other studies $(1,4)$, amniocentesis is a safe procedure with minimal and short-term consequences on fetal hemodynamics. We hope these findings provide a basis for relevant future research.

\section{Cantekin İskender ${ }^{1}$, Ebru Tarım ${ }^{2}$}

${ }^{1}$ Department of Perinatology, Zekai Tahir Burak Womens Health Research and Training Hospital, Ankara, Turkey

${ }^{2}$ Department of Perinatology, Başkent University Faculty of Medicine, Adana, Turkey

\section{References}

1. Iskender C, Tarım E, Cok T, Kalaycı H, Parlakgümüş A, Yalçınkaya C. Does bleeding affect fetal Doppler parameters during genetic amniocentesis? J Turk Ger Gynecol Assoc 2014; 15: 100-3. [CrossRef]

2. Vanlieferinghen S, Bernard JP, Salomon LJ, Chalouhi GE, Russell NE, Ville Y. Second trimester growth restriction and underlying fetal anomalies. Gynecol Obstet Fertil 2014; 42: 567-71. [CrossRef]

3. Lazebnik N, Many A. The severity of polyhydramnios, estimated fetal weight and preterm delivery are independent risk factors for the presence of congenital malformations. Gynecol Obstet Invest 1999; 48: 28-32. [CrossRef]

4. Artunc Ulkumen B, Pala HG, Baytur YB, Koyuncu FM. Ductus Venosus Doppler Flow Velocity after Transplacental and Nontransplacental Amniocentesis during Midtrimester. Pak J Med Sci 2014; 30: 992-5. 